\title{
Performance Evaluation of Small-Scale Solar Powered Wastewater and Grey Water Treatment Systems
}

\author{
Jameelu S. Abaya ${ }^{a, *}$, Rabee Rustum $^{b}$, and Don Ashan Haputantri ${ }^{c}$ \\ ${ }^{a}$ Department of Civil and Environmental Engineering, United Arab Emirates University, Al Ain, UAE \\ ${ }^{b}$ Institute of infrastructure and Environment, Heriot-Watt University \\ ${ }^{c}$ Department of Operations, ARMS Group, Dubai, UAE
}

\begin{abstract}
Onsite wastewater treatment systems are the most economical way of dealing with used water in an isolated environment. And because of the variability normally associated with the operation of these systems is linked to either varying hydraulic loading or the nature of the environment in which the system was installed, the performance of these systems needs to be evaluated to find out the optimum operating condition. In this work, the performance of two small-scale treatment systems used for wastewater and gray water was evaluated. This was done by comparing the measure of some physical, chemical and biological parameters in the effluent to the standards of effluent discharge sets by Dubai Municipality. The performance was also measured from other angles using the proposed Swedish Water and Wastewater Association performance indicators so as to give the analysis a wider coverage of economic and energy consumption. The result shows that the performance of the installed solar-powered treatment systems was enough to meet the requirements set by Dubai municipality for effluent discharge except for Ammonia-Nitrogen. Also, the deployment of solar power energy supply, coupled with a low energy usage of the two systems, has made this particular setting an environmentally sustainable setting for such an isolated site.
\end{abstract}

\section{Introduction}

As human race steps further into the 21 st century, the issues regarding water and wastewater on one hand and power supply on the other hand, are becoming critical. This is not only in the mind of researchers and operators of the relevant industries, but also at the heart of those who have concern for what is going on around the planet in relation to its sustainability as a preparation for leaving a bright future for the coming generations. Water and power are very much interrelated and sometimes interdependent; depending on what source the power is being generated from [1,2,3]. Though, there are potential alternatives to power sourced from oil (no matter their disadvantages), oil wells are continuously drying and will be drained in a near future. On the other hand, water has no potential alternatives; it is a finite quantity, but faces a rapid increase in demand by geometrically increasing population, particularly in urban settlements, and their mostly extravagant lifestyle. For that, water re-use remains an essential practice to conserve water resources. Use of treated wastewater/gray water reduces the burden on fresh water, though, at the same time, it is significantly increasing the demand of energy for treatment and transportation.

${ }^{*}$ Corresponding author

Email: jameelu.s@uaeu.ac.ae; jamiluabaya@yahoo.com

(C) 2015 International Association for Sharing Knowledge and Sustainability

DOI: $10.5383 /$ swes.7.01.004
Gray water is the wastewater generated in homes or workplaces while bathing, cooking or washing [6]. It is characterized by lifestyle, water use, social and cultural behavior of the users as well as the organic loading which constantly varies [7]. Being a component of wastewater, all Wastewater Treatment (WWT) methods can be regarded as gray water treatment methods as well. However, since it is not as polluted as wastewater, some WWT methods are often considered for its treatment $[6,8]$ based on efficiency of treatment, simplicity of technology and the cost of construction or purchase [9]. The most cherished methods include Sequence batch reactor, Membrane bioreactor, Rotating biological contractor, Intermitted sand filter, Constructed wetland and Septic tank $[6,8,9,10,11]$.

The use of renewable sources of energy to drive the machinery in water and all Wastewater Treatment Systems (WWTSs) is the only way-out to save water and WWT industries from the escalating energy problem. Solar energy, in particular, possesses the most promising potential among all the technologically proven renewable energy sources $[13,14,15]$. Therefore, use of solar energy to power treatment system (TS) or as a facilitator of disinfection will no doubt considerably reduce the resources consumed in WWTS and also the amount of pollutants released to air and water bodies during these 
processes. Overall, it could be an improvement on the common philosophy of WWT. Another form of renewable energy that could help is the wind energy. Small scale wind turbines are available in the market with a generation capacity enough to meet the energy requirement of the TSs.

To design a PV system, variations in terms of electricity demand and solar radiation have to be determined on daily, weekly and seasonal basis. The orientation of the PV arrays and the angle to which it should be tilted to must also be determined. The size/capacity of the battery is also required. The capital cost of PV systems might be high, but the cost of managing it is very low compared to other sources of energy system including the renewable.

When dealing with small communities, WWTS always faces constraint(s) due to specific site conditions ranging from variability of hydraulic and organic loads to the need of simplicity for handling and operating [16]. This implies that any newly established system of treatment ought to be optimized for the ultimate performance of its components to give the best possible desired quality of effluent so as to match with the set standards [12] of the regulatory agencies, in this case, the Dubai Municipality. The two TSs for sewage and gray water treatment were designed and put into use in Australia. And because Australia has a different climate condition from United Arab Emirates (UAE), the system must be evaluated if it is to be used in Dubai and most especially because of the effluent is intended to be used for lawn and dust control. The difference of average maximum temperature between Dubai and most of the cities in Australia is between $8^{\circ} \mathrm{C}$ to $15^{\circ} \mathrm{C}$, wide enough to double the rate of chemical reaction, significantly enough to alter the system efficiency. Hence, in addition to other points mentioned above, the need for the evaluation of the system becomes necessary.

This research aims to evaluate the performance of onsite wastewater/gray water TSs. First, the effluent characteristics were measured in terms of BOD5, COD, and Residual chlorine concentration, and Nitrogen for four (4) consecutive months. Suspended Solids (SS) and sludge characteristics of the aerated Mixed Liquor Suspended Solids (MLSS) in the aeration tank were also measured for the same period. Secondly, the qualities of the effluents were compared with the standard sets by Dubai municipality for effluent discharge for use in irrigation. Thirdly, Critical analysis of the data obtained using the scientific method and facts from the existing literature to obtain the optimum 'point' of operation of the systems. Finally, possible mitigations were provided for the problems identified and some possible improvement(s) for the systems suggested.

\section{Methods and Materials}

\subsection{Case Study}

The plants are small scale wastewater (RP10) and grey water (GTS10) TSs, designed and produced by OzziKleen Technology, and installed in Gulf Ventures Desert Safari Camp located at Al Awir, Dubai, UAE. Geographically, it is at latitude $25^{\circ} 9^{\prime} 13.18^{\prime \prime} \mathrm{N}$ and longitude $55^{\circ} 34^{\prime} .6$ 05” E. RP10 was connected to the water closet to collect the black water while wastewater from shower tray and wash basin was piped to GTS10.

The two systems were designed to carry flow from ten person's population equivalent (p.e.) with moderate water use. Although, the camp hosts an average of 100 guests per day normally staying for about $5 \mathrm{hrs}$, the tanks have sufficient capacity to treat the wastewater. Water consumption was known to be very low and the estimate was made at $25 \mathrm{~L} / \mathrm{p} / \mathrm{d}$.
This estimate will leave an excess volume of 2500 liters/day. The case study is depicted in Fig.1. The two systems (Fig. 2) are dimensionally the same from outside, but slightly different inside, which is of course because of the difference in the function they have to perform. Unlike GTS 10, RP10 (colored green) contains sludge tank in addition to other components of the TS.

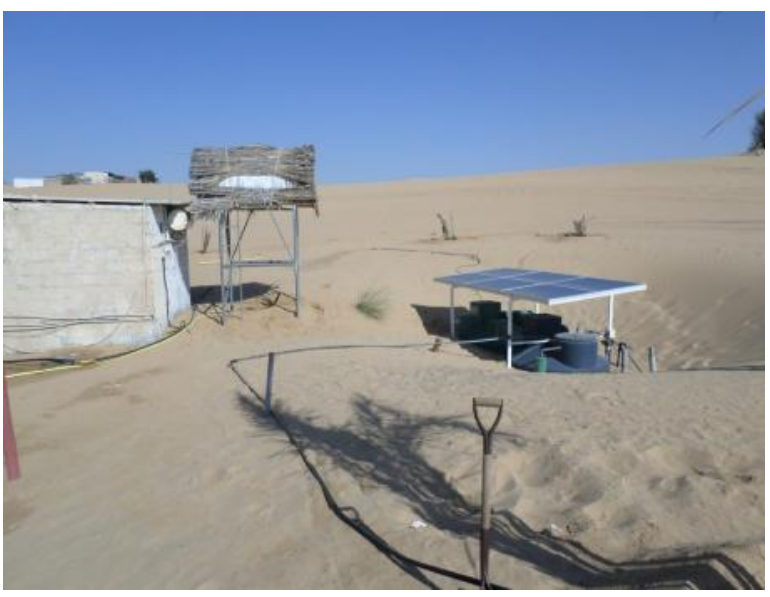

Fig. 1 RP10 and GTS10 Installed in Gulf Venture's Dnata's Deserts Safari Camp

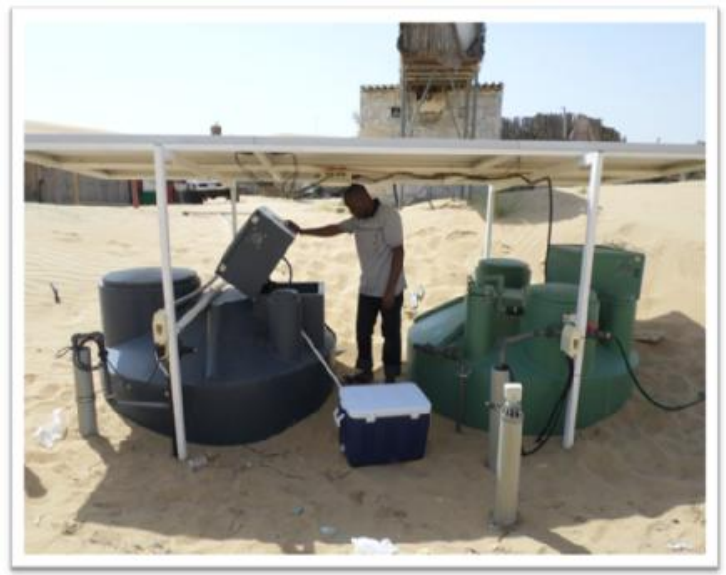

Fig. 2: Inspection of the GTS10 System at the Dnata Desert Safari Camp

The main components that constitute the main body of the TSs are made up of medium density polyethylene material; these include the Main tank, Sludge tank, Chlorine tank, Motor box and Stilling well. Polyvinyl chloride pipes were used in the plumbing system. Other components are electrical and mechanical equipment such as Air blower, Effluent pump, and Control. Fig. 3 shows the plan and horizontally oriented crosssectional views of RP10. Operations of the systems are carried mainly in seven (7) components (Fig. 4) controlled using the automatic control system. Operation cycles (for aeration, settling and decanting) are selected and set by the operator/installer in the control system. 


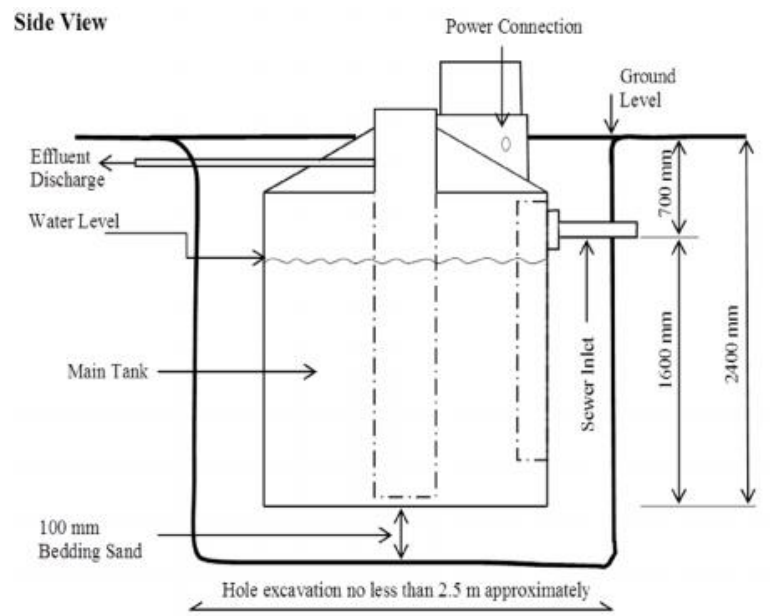

Top View

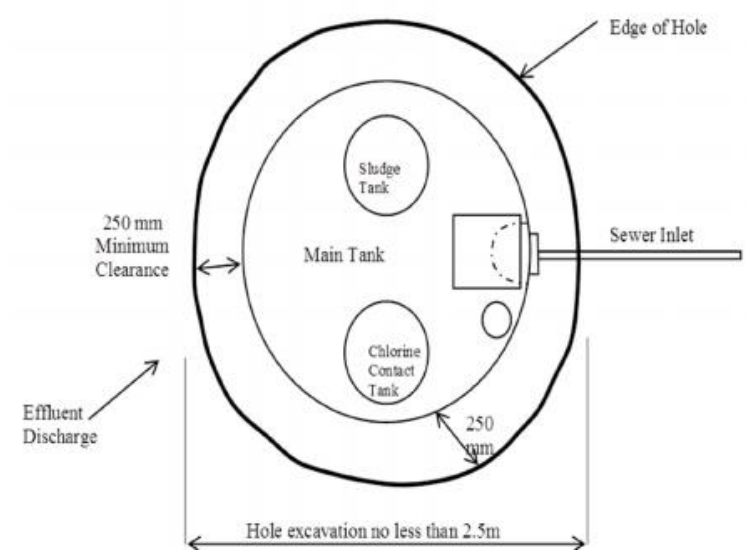

Fig. 3: Top and Side View of RP10 Tank as Per the Installation Specification

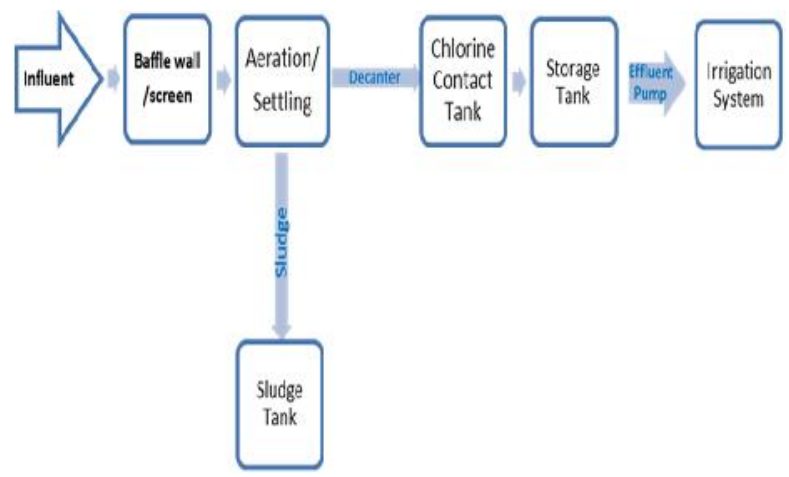

Fig. 4: Flow Chart of RP10 and GTS10 Operation

\subsection{Solar Power System (SPS) Components}

The solar panels are six in number each having a capacity of producing $230 \mathrm{~W}$ under an operating temperature range of $40^{\circ} \mathrm{C}$ to $80^{\circ} \mathrm{C}$. Each of the six Poly-Si, class 'A' panels weigh $19.5 \mathrm{~kg}$ and have a dimension of $1650 \times 992 \times 50 \mathrm{~mm}$ capable of producing a maximum voltage of $1000 \mathrm{~V}$ DC.
In total, the six panels can produce power up to $13.110 \mathrm{kWh}$ per day under an average sunshine of 9.5 hours per day. The PV system can be sized as follows [17, 18]: First, the daily power required is estimated from appliance's daily power use and allowing for about $30 \%$ to cater for system inefficiency. Secondly, the number of panels required is obtained as a ratio of the power required to panel's power generation capacity. Thirdly, the inverter is sized based on the arithmetic sum of the appliance's power usage with a merging allowance of $25-30 \%$ to cater for unexpected loading. Finally, the number of batteries required as a ratio of total expected amps from panels and total amps of a battery at maximum discharge.

The operation cost of energy tapped from the grid is based on Dubai Electricity and Water Authority's billing while that of the generator is based on average fuel consumption for the diesel generator, gal $/ \mathrm{h}$.

\subsection{Treatment System Performance and Reliability}

The standard set by the regulatory authority is the most important parameters to select/design a treatment plant that is reliable and can perform the best treatment [4]. For this research, some experiments were conducted onsite viz., settleometer test, $\mathrm{SV} 30, \mathrm{pH}$, residual chlorine test and temperature. Whereas the remaining experiments: BOD, COD and Total SS, Total coliform, Ammonia Nitrogen and E. Coli were conducted in the Dubai central laboratory (DCL).

Discussion of the results was covered under the umbrella of six performance indicators (PIs) provided by [19] for Swedish Water and Wastewater Association (SWWA). SWWA PIs has versatility and completeness as complemented by the developers; the PIs are detailed up to operator level deeply covered than International Water Association's manual, they also expand beyond cost and energy contained in well adopted Austrian benchmarking system. The PIs used are in a form of simple ratio with the numerator as a representative of the cost or consumption while the denominator represents loads or performance factor on the plant. It could be noticed that not all the proposed PIs were used in the analysis as they were derived based on conventional large size TSs, as such, not all the elements of the PIs can be applied on onsite TSs. Elements or points of analysis such as 'energy sold' and 'biogas production' were not included since they are not commonly associated with onsite TSs. The PIs analyzed are Effluent quality, Sludge and sludge quality, Energy, Chemical consumption, Personnel and Economy.

\section{Results and Discussion}

\subsection{Sludge and Sludge Quality}

The philosophy behind the performance of this test is to find out the settleability of the aerated MLSS in the aeration tank. Other important observations made are clarity of the supernatant and the volume of the biomass as it settles (Fig. 5). This method is very important in finding the effectuality of a treatment process which is necessary since the quality of AS biomass could be affected by the change in duration or frequency of the aeration process. The result of the settleometer test conducted over four months at an interval of two weeks. The test was carried out only on RP10 as gray water does not contain a significant amount of sludge. During the period of study, the period of the three cycles (Table 1) was varied in anticipation of obtaining a better effluent quality. 
Table 1: System Settings, RP 10 and GTS 10

\begin{tabular}{|c|c|c|c|c|c|c|c|c|c|c|c|c|c|c|c|c|c|c|c|c|}
\hline \multirow{3}{*}{ Cycle } & \multicolumn{20}{|c|}{ Period (minutes) } \\
\hline & \multicolumn{2}{|c|}{ Week 1} & \multicolumn{2}{|c|}{ Week 2} & \multicolumn{2}{|c|}{ Week 3} & \multicolumn{2}{|c|}{ Week 4} & \multicolumn{2}{|c|}{ Week 5} & \multicolumn{2}{|c|}{ Week 6} & \multicolumn{2}{|c|}{ Week 7} & \multicolumn{2}{|c|}{ Week 8} & \multicolumn{2}{|c|}{ Week 9} & \multicolumn{2}{|c|}{ Week 10} \\
\hline & $\mathrm{RP}$ & GTS & $\mathrm{RP}$ & GTS & RP & GTS & RP & GTS & RP & GTS & RP & GTS & $\mathrm{RP}$ & GTS & RP & GTS & RP & GTS & RP & GTS \\
\hline Aeration & 60 & 60 & 60 & 60 & 60 & 60 & 60 & 60 & 60 & 60 & 60 & 60 & 60 & 60 & 60 & 60 & 60 & 60 & 60 & 60 \\
\hline Settling & 30 & 30 & 30 & 30 & 30 & 30 & 30 & 30 & 60 & 60 & 60 & 60 & 60 & 60 & 60 & 30 & 60 & 30 & 30 & 30 \\
\hline Decanting & 30 & 30 & 30 & 30 & 30 & 30 & 30 & 30 & 30 & 30 & 30 & 30 & 30 & 30 & 30 & 30 & 30 & 30 & 30 & 30 \\
\hline
\end{tabular}

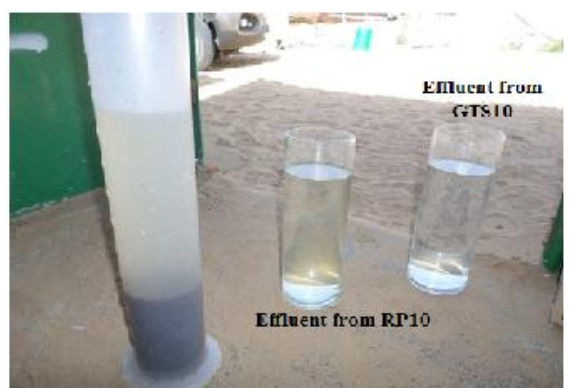

Fig. 5: Settleometer Test for RP10 (Sample from Aeration Tank; Taking during the Aeration Period)

Over the period of this study, the sludge settling characteristics of the system appears to have divided itself into two groups (Fig. 6): low-level slow settling sludge and high-level slow settling sludge. Both groups have a curved settling plot; a characteristic of good quality sludge. The lowlevel slow settling sludge appears to have a slower rate of settling, thereby characterizing it as a relatively young age sludge. This can be more confidently said since there was no any sign of sludge bulking noticed during the experiment and that the system itself is known to be new, started without any sludge seeding.

The shape of the curve is also influenced by the nature of loading on the system, the concentration of dissolved oxygen (DO) and temperature of the sample but insensitive of the sludge concentration [20]. As such, over time, average values could be established and could be used to define the sludge characteristics of the system in this particular site. The averaged values (Fig. 7) falls below the 'ideal curve' for the system [21] although 60_60_30 settings yielded a closer ranged curve compared to the 60_30_30 settings. 60_60_30 settings curve collimate very well with the ideal curve given a good indication of good settling property of the sample.
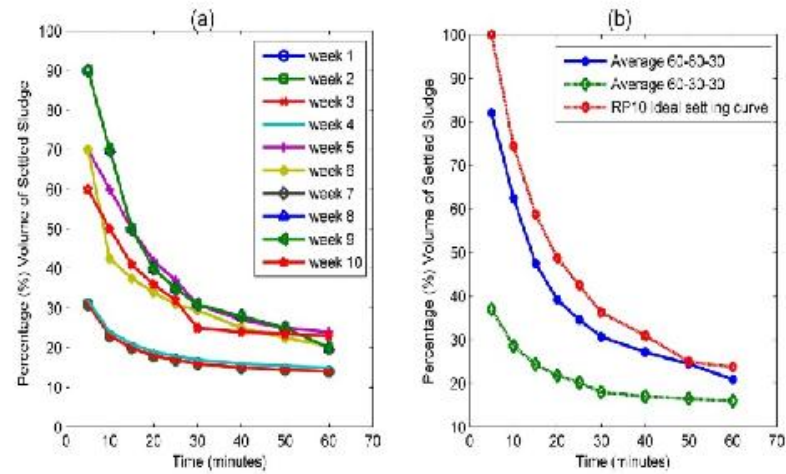

Fig. 6: Settling Curve for RP10 (Weekly Values)

Fig. 7: Settling Curve for RP10 (Averaged Values vs. Ideal curve)

\subsection{Effluent Quality and Chemical Consumption}

Table 2 show biological and physicochemical parameters for RP10 and GTS10 respectively, samples taken from the effluent tank. Except for Ammonia-Nitrogen (NH3-N) in RP10, the quality of effluent produced by both RP10 and GTS 10 and tested during this research has been good enough to meet the standards of wastewater discharge limits for irrigation (drip and spray) sets by the municipality. The quantity of NH3-N present in the effluent has been fluctuating above $0.2 \mathrm{mg} / \mathrm{L}$ limit. Therefore, improvement is needed to bring down the concentration NH3-N being produced by the system. But, the result here is not enough to conclude on the nitrification efficiency of the system as the concentration(s) of NH3-N in the influent(s) is not available. The $\mathrm{pH}$ values are all within the normal range of irrigation water (6.5-8.5). They are not too high to cause alkalinity or too low to instigate acidity.

In the entire treatment processes, chemicals are consumed only during disinfection. Each of the systems consumes nine $5.5 \mathrm{ppm}$ stabilized chlorine tablets every 3 months. Each tablet costs 4 AED. Therefore, each of these systems used only $1.37 \mathrm{AED} /$ p.e./year for disinfection.

\subsection{Energy}

The daily power usage of the two systems was estimated at 8960 W.h from $800 \mathrm{~W}$ (1 hr working) and 400W (9.9hr working) consumed by effluent pump and the other components respectively. By adding $20 \%$ for inefficiency and 9.6 daily sunshine hours, the daily power required is 1120 W. Number of panels required were obtained as 5 panels (230W each) and the inverter sized at $3000 \mathrm{~W}$ including a small margin. The number of batteries required is $8,100 \mathrm{~A} . \mathrm{h}$, $50 \%$ maximum discharge batteries. The cost of operation using energy tapped from the grid is $99 \mathrm{AED} /$ month while that of using a generator $(2.4 \mathrm{kWh}, 0.6 \mathrm{gal} / \mathrm{h})$ is 6058 AED/month.

The effectiveness of the total power usage of the two systems could be understood by comparing it with that of 22 other TSs studied by [19]. The average of the 22 systems studied was approximately $60 \mathrm{kWh} / \mathrm{p}$.e./year, the highest of which was 144 and $39 \mathrm{kWh} /$ p.e./year the lowest. Where else in this study, the total power usage was estimated at 32 $\mathrm{kWh}$ /p.e./year. This indicates that the two system's power usage is $28 \mathrm{kWh} / \mathrm{p} . \mathrm{e} . / \mathrm{year}$ less than the average of those 22 WWTSs and $7 \mathrm{kWh} / \mathrm{p}$.e./year less than the lowest among them. The system's power usage could even be regarded as more effective considering the shreds of evidence showing that onsite TSs generally consume more power per p.e. than centralized TSs.

Another perspective that could be used to weigh the system's performance is the purchased energy. The purchased energy as per as SPS is a concern is zero, as the source of the energy (sun) is free. For connection to the national grid or running 
with a diesel generator, there is quite a clear difference in the amounts as indicate by the estimate mentioned above.

What could bring some significant difference is the capital cost of construction/purchase of the power supply system. The entire solar powering system $(5 \mathrm{~kW})$ cost 48,000 AED, though the cost of connecting to the grid could not be verified, generator with similar capacity, cost around 5000 AED each (at least two sets must be provided for continued operation). This still leaves the SPS with the upper hand over others as per as purchased energy is concerned.

\section{Conclusion}

The RP10 and GTS10 TSs are fully automated, does not require any personnel to be stationed specifically for their operation. Except if there is a malfunction alarm, the systems are only checked monthly.

The results obtained (Fig. 7) show that RP10 is performing excellently in the installed condition as per as sludge yield is concerned. And that the best system setting which yielded sludge with best settling characteristics and better effluent quality is 60_60_30. That is, 60 minutes aeration, 60 minutes settling and 30 minutes decanting periods.

Except for Ammonia-Nitrogen, the quality of effluent produced by both RP10 and GTS 10 has been good enough to meet the standards of wastewater discharge limits allowable for irrigation (drip and spray) sets by Dubai municipality.

The quantity of Ammonia-Nitrogen present in the effluent has been fluctuating above the $0.2 \mathrm{mg} / \mathrm{L}$ limit. Therefore, a measure to control the nitrification needs to be employed. It could be a chemical process such as the addition of Alum in the aeration tank or physical process such as adding a new treatment unit after the disinfection chamber. The unit to be added could be Activated Carbon.

Chemicals consumption is minimal and is only employed for final disinfection. 9 chlorine tab per month per TS at 4 AED per tab or $1.37 \mathrm{AED} / \mathrm{p} . \mathrm{e} . /$ year for chlorine disinfection is quite economical. However, it is suggested that the disinfection method of the two systems be changed to ultraviolent or any other non-chemical method of disinfection since there is sufficient free energy to run the systems. This can replace the chlorine disinfection which is, however, cheap and effective but may have a potential harmful effect of the soil in a long run.

In comparison with the 22 TSs studied by [19], the total power usage estimated at $32 \mathrm{kWh} /$ p.e./year is quite encouraging. The system's power usage could even be given better regard if the pieces of evidence showing that onsite TSs generally consume more power per population equivalent than centralized TSs.

Looking at the systems from energy purchase perspective, analysis favored the SPS over purchase from the national grid and use of diesel generator. The capital cost of the solar powered system is also high like that of the diesel while the cost of connection to the national grid could not be verified. There is no operation cost attached to the SPS while the other two have a quite substantial cost of fuelling or billing.

The use of the treated wastewater/gray water obtained from these systems will not only serve as a remedy for the use of the fresh water, it will in addition to that, serve as a 'saviour' of the environment and promoter of qualitative public health. However, further research should be conducted to enhance the performance of the system. Performance analysis of TSs are usually conducted based on long period records, as such, the performance of the systems would be best explained if studied for a longer period of time say a year or more. In addition, a different method of sludge analysis could be used while conducting another performance analysis. Sludge Volume Index method; in particular, is good in bringing out valuable information about the sludge [20,5]. Furthermore, Mechanical reliability analysis of the systems was not conducted because of time and financial constraints. It is therefore recommended that it should be conducted as suggested by [4].

\section{Acknowledgements}

The authors are grateful to the operation department of ARMS group, Dubai, UAE for providing the permit and necessary assistance to conduct this research.

\section{References}

[1] Merce A, Carrillo R, Frei, C. Water: A key resource in energy production. Energy Policy 2009;37:4303-4312

[2] Siddiqi A, Anadon LD. The water-energy nexus in Middle East and North Africa. Energy Policy 2011;39:4529-4540

[3] UN. World Water Day 2014 Advocacy Guide; water and energy. UN Water, United Nations University (UNU) and United Nations Industrial Development Organization www.unwater.org/worldwaterday

(UNIDO).

[4] Spellman FR. Hand book of water and wastewater treatment plant operation. 2nd ed. London: CRC Press; 2009.

[5] Lin SD,Lee CC, editors. Water and wastewater calculations manual. 2nd edition, London: Mcgraw-hill; 2007.

[6] Ghaitidak DM, Yadav KD. Characteristics and treatment of greywater-A review. Environ Sci Pollut Res 2013; 20(5): 2795-2809.

[7] Jefferson B, Palmer A, Jeffrey P, Stuetz R, Judd S. Grey water characterization and its impact on the selection and operation of technologies for urban reuse. Water Sci Technol 2004; 50:157-164.

[8] Ghunmi LA, Zeeman G, Fayyad M, van Lier JB. Greywater treatment systems: A review. Critical Rev in Environ Sci Technol 2011; 41(7):657-698.

[9] Ahmed M, Arora M. Suitability of Grey Water Recycling as decentralized alternative water supply option for Integrated Urban Water Management. IOSR $\mathbf{J}$ of Eng 2012; 2 (9):31-35.

[10] Gulyas H. Greywater reuse-Concepts, benefits, risks and treatment technologies. In International Conference on Sustainable Sanitation-Food and Water Security for Latin America, Fortaleza, Ceará, Brazil 2007, November

[11] Allen L, Christian-Smith J, Palaniappan M. Overview of greywater reuse: the potential of greywater systems to aid sustainable water management. 2010; Pacific Insfitute, www. pacinst. org.

[12] Otterpohl R. Design of highly efficient Source Control Sanitation and practical Experiences. EURO Summer School DESAR, Wageningen; 2000. 
[13] Swenson, R. The production peaks in petroleum and natural gas: information, misinformation, awareness, and implications. In: Proceedings of the ISES 2005 solar world congress; 2005.

[14] De Vries BJ, van Vuuren DP, Hoogwijk MM. Renewable energy sources: Their global potential for the first-half of the 21 st century at a global level: An integrated approach. Energy policy 2007; 35(4): 25902610.

[15] Hoogwijk M, Graus W. Global potential of renewable energy sources: a literature assessment. Background report; 2008. http://www.ecofys.com/files/files/report_global_potenti al_of_renewable_energy_sources_a_literature_assessm ent.pdf

[16] Al Baz I, Otterpohl R, Wendland C, editors. Efficient Management of Wastewater: Its Treatment and Reuse in Water-Scarce Countries, Berlin; MEDA: Water Springer; 2008.
[17] LEONICS. How to design solar PV system: Guide for sizing your solar photovoltaic system. LEONICS CO.,LTD.http://www.leonics.com/support/article2_12j /articles2_12j_en.php [accessed 6 November, 2014]

[18] WSUEEP. Solar Electric System Design, Operation and Installation: An Overview for Builders in the Pacific Northwest. Washington: Washington State University Extension Energy Program (WSUEEP); 2009.

[19] Balmér P, Hellström D. Performance indicators for wastewater treatment plants. Water Sci Technol 2012; 65(7):1304 - 1310

[20] Janczukowicz W, Szewczyk M, Krzemieniewski M, Pesta J. Settling properties of activated sludge from a sequencing batch reactor (SBR). Polish J Environ Stud2001; 10(1):15-20.

[21] OZZI KLEEN (2011) Installation manual: domestic sewage treatment plant RP10 and GTS10 model. 
Abaya et al. / Int. J. of Sustainable Water \& Environmental Systems, 7 (2015) 29-35

Table 2: Biological and Physico-Chemical Parameters for RP10 and GTS 10 (Sampled from Effluent Tank)

\begin{tabular}{|c|c|c|c|c|c|c|c|c|c|c|c|c|c|c|c|c|c|c|c|c|c|c|c|c|c|c|}
\hline \multirow{4}{*}{ S/No } & \multirow{4}{*}{ Parameter } & \multirow{4}{*}{ Units } & \multirow{4}{*}{$\begin{array}{c}\text { Test } \\
\text { Method }\end{array}$} & \multicolumn{3}{|c|}{ Maximum Allowable Limits } & \multirow{2}{*}{\multicolumn{20}{|c|}{ Values }} \\
\hline & & & & \multirow{3}{*}{$\begin{array}{c}\text { Sewerage } \\
\text { System }\end{array}$} & \multicolumn{2}{|c|}{$\begin{array}{l}\text { Land as for } \\
\text { Irrigation }\end{array}$} & & & & & & & & & & & & & & & & & & & & \\
\hline & & & & & \multirow{2}{*}{ Drip } & \multirow{2}{*}{ Spray } & \multicolumn{2}{|c|}{ Week 1} & \multicolumn{2}{|c|}{ Week 2} & \multicolumn{2}{|c|}{ Week 3} & \multicolumn{2}{|c|}{ Week 4} & \multicolumn{2}{|c|}{ Week 5} & \multicolumn{2}{|c|}{ Week 6} & \multicolumn{2}{|c|}{ Week 7} & \multicolumn{2}{|c|}{ Week 8} & \multicolumn{2}{|c|}{ Week 9} & \multicolumn{2}{|c|}{ Week 10} \\
\hline & & & & & & & $\mathrm{RP}$ & GTS & $\mathrm{RP}$ & GTS & $\mathrm{RP}$ & GTS & $\mathrm{RP}$ & GTS & $\mathrm{RP}$ & GTS & $\mathrm{RP}$ & GTS & RP & GTS & RP & GTS & $\mathrm{RP}$ & GTS & RP & GTS \\
\hline 1. & $\begin{array}{l}\text { Biological } \\
\text { Oxygen } \\
\text { Demand }\end{array}$ & $\mathrm{mg} / \mathrm{L}$ & $\begin{array}{c}\mathrm{SOP}-\mathrm{FE} \\
1112\end{array}$ & 1000 & 20 & 10 & $<7$ & $<7$ & & & & & $<7$ & $<7$ & & & & & & & & & & & $<7$ & \\
\hline 2. & $\begin{array}{l}\text { Chemical } \\
\text { Oxygen } \\
\text { Demand }\end{array}$ & $\mathrm{mg} / \mathrm{L}$ & $\begin{array}{c}\mathrm{SOP}-\mathrm{FE} \\
1123\end{array}$ & 3000 & 100 & 50 & 19 & 14 & & & & & 25 & 14 & & & & & & & & & & & 22 & \\
\hline 3. & $\begin{array}{l}\text { Chlorine } \\
\text { residuals }\end{array}$ & $\mathrm{mg} / \mathrm{L}$ & onsite & 10 & $\begin{array}{r}\text { Not le } \\
30 \\
\text { cont }\end{array}$ & $\begin{array}{l}\text { han } 0.5 \\
\text { rr } \\
\text { untes } \\
\text { time }\end{array}$ & 0.6 & 1.0 & 0.6 & 1.0 & 0.6 & 0.6 & 0.6 & 1.0 & 0.5 & 0.6 & 0.6 & 0.5 & 0.5 & 0.5 & 0.5 & 0.4 & 0.5 & 0.5 & 0.4 & 0.5 \\
\hline 4. & $\mathrm{pH}$ range & Units & onsite & $6-10$ & $6-8$ & $6-8$ & 7.2 & 7.6 & 7.2 & 7.6 & 7.2 & 7.2 & 7.2 & 7.6 & 7.2 & 7.4 & 6.8 & 7.8 & 7.8 & 7.8 & 7.8 & 7.2 & 7.8 & 7.2 & 7.8 & 7.2 \\
\hline 5. & $\begin{array}{c}\text { Total } \\
\text { Suspended } \\
\text { Solids }\end{array}$ & $\mathrm{mg} / \mathrm{L}$ & $\begin{array}{c}\mathrm{SOP}-\mathrm{FE} \\
1104\end{array}$ & 500 & 50 & 11 & $<11$ & $<11$ & & & & & 21 & $<11$ & & & & & & & & & & & & \\
\hline 6. & $\begin{array}{c}\text { Temperatur } \\
\mathrm{e}\end{array}$ & ${ }^{0} \mathrm{C}$ & onsite & $\begin{array}{l}45>5 \text { of } \\
\text { Ambient }\end{array}$ & & & 33.3 & 33.2 & $\begin{array}{c}33 . \\
3\end{array}$ & 33.2 & $\begin{array}{c}33 . \\
3\end{array}$ & 33.3 & $\begin{array}{c}32 . \\
1\end{array}$ & 33.2 & 30 & 30 & 29 & 29 & 28 & 28 & 27 & 33.1 & 26 & 32.1 & $\begin{array}{c}31 . \\
5\end{array}$ & 31.5 \\
\hline 7. & $\begin{array}{c}\text { Total } \\
\text { Coliform }\end{array}$ & $\begin{array}{c}\mathrm{CPU} / 100 \\
\mathrm{ml}\end{array}$ & $\begin{array}{l}\text { SOP - FE } \\
1601\end{array}$ & 500 & 1 & 1 & $<1$ & $<1$ & & & & & $<1$ & $<1$ & & & & & & & & & & & $<1$ & \\
\hline 8. & $\begin{array}{l}\text { Ammonia } \\
\text { Nitrogen }\end{array}$ & $\mathrm{mg} / \mathrm{L}$ & $\begin{array}{l}\text { SOP - FE } \\
1112\end{array}$ & & 0.2 & 0.2 & 0.3 & $<0.2$ & & & & & 0.2 & $<0.2$ & & & & & & & & & & & 0.5 & \\
\hline 10. & $\begin{array}{l}\text { Escherichia } \\
\text { Coli }\end{array}$ & $\begin{array}{c}\mathrm{CPU} / 100 \\
\mathrm{ml}\end{array}$ & $\begin{array}{c}\text { SOP - FE } \\
1601\end{array}$ & & 1 & 1 & $<1$ & $<1$ & & & & & $<1$ & $<1$ & & & & & & & & & & & - & \\
\hline
\end{tabular}

